\title{
Road traffic accidents among alcohol-dependent patients: The effect of treatment
}

\author{
M. Trinidad Gómez-Talegón, F. Javier Alvarez* \\ Institute for Alcohol and Drug Studies, Faculty of Medicine, University of Valladolid, 47005 Valladolid, Spain
}

Received 18 March 2005; accepted 15 September 2005

\begin{abstract}
It is well known that driving under the influence of alcohol increases the risk of traffic accidents. Alcohol-dependent patients are responsible for two-thirds of motor vehicle crashes involving alcohol. Studies carried out on the general population have shown a relation between alcohol dependence and traffic accidents.

The aim of the study is to analyse the effect on traffic accidents of treatment of patients with alcohol-related problems. To do so, the prevalence of traffic problems in a sample of patients with a diagnosed dependence on alcohol was assessed for three periods: during their lifetime, in the year preceding the start of treatment and over the year of treatment.

A prospective study was carried out of 176 patients (147 males, 29 females; mean age 42.9 years) diagnosed as alcohol dependent according to the DSM-IV criteria in three alcoholic treatment centres in Castilla y León, Spain.

$36.9 \%$ of the alcohol-dependent patients had had some kind of traffic problem during their life and $8.5 \%$ in the year prior to starting treatment. The most frequent problem was positive breath tests, followed by accidents with damage to the vehicle. Sixty-nine of the 176 patients were still receiving treatment after a year. The prevalence of traffic problems among those patients who followed treatment for 1 year (4.3\%) was lower than in the year before treatment $(15.9 \%)$.

The study showed that the treatment is also effective in reducing traffic problems.
\end{abstract} (C) 2005 Elsevier Ltd. All rights reserved.

Keywords: Traffic violations; Traffic collisions; Alcoholism; Alcoholism treatment

\section{Introduction}

Alcohol consumption is a factor that frequently influences the occurrence of injuries and accidents, especially in road traffic accidents (Haberman, 1987; Chipman, 1995), with the resulting morbidity and mortality which create an important public health problem on a worldwide level (WHO, 2004).

Spain is one of the countries where the consumption of alcoholic beverages and its related problems acquire great importance, due to the high prevalence of consumption, the deep-rooted social acceptance the habit has in our communities and the generalised perception that alcohol, or at least certain kinds of alcoholic beverage, are part and parcel of our society's alimentary and dietary norms (Del Río et al., 2001).

It is well known that driving under the influence of alcohol increases the risk of being involved in a traffic accident (Zador,

\footnotetext{
* Corresponding author. Tel.: +34 983 423077; fax: +34 983423022.

E-mail address: alvarez@med.uva.es (F.J. Alvarez).
}

1991; Maycock, 1997). It has been estimated that for every $0.02 \mathrm{~g} / \mathrm{l}$ of increase in a driver's blood-alcohol concentration, the risk of being involved in a road traffic accident doubles. In general, the effects of alcohol on the psychomotor performance and involvement in accidents are directly proportional to the level of alcohol in the blood: the higher the level, the greater the deterioration.

Alcohol-dependent patients are responsible for two-thirds of motor vehicle crashes involving alcohol (Hingson et al., 2002). The first evidence to show that alcohol-dependent patients were more prone to road traffic accidents appeared in the mid-20th century (Schmidt et al., 1962; Waller and Turkel, 1966).

Studies carried out on the general population have shown a relation between alcohol dependence and road traffic accidents. Thus, in the USA, in the National Longitudinal Alcohol Epidemiologic Survey of 1992, thirteen percent of respondents were considered to fulfil the DSM-IV criteria of alcohol dependence at some point in their lives. These people with alcohol dependence represent $65 \%$ of those involved in a traffic accident due to the excessive consumption of alcohol and make up $72 \%$ of 
those who had had a traffic accident in the year prior to carrying out the study (Hingson et al., 2002). From the data of the Fatal Accident Reporting System (FARS) and the National Mortality Follow-Back Survey (NMFS) in the USA, those involved in fatal accidents with BACs $\geq 0.15 \mathrm{~g} / \mathrm{dl}$ were more frequently classified by their families as "problem drinkers" or "hard core" than those with BACs of $0 \%$ (31\% versus 1\%) (Baker et al., 2002).

In a previous study carried out on 8043 drivers who attended the Medical Driving Test Centres to evaluate their fitness to drive, it was seen that among the people diagnosed as having alcoholrelated problems, $23.2 \%$ of these admitted to a traffic accident in the 3 years preceding the survey and $18.7 \%$ said they had been fined in the year preceding the survey. These figures are significantly higher than those obtained for those who did not have alcohol-related problems $(12.1 \%, 9.3 \%$, respectively) (Del Río et al., 2001).

Several studies have shown that brief interventions or counselling for alcohol problems among patients involved in alcoholrelated injuries are effective in reducing drink-driving offences and alcohol-related injuries (Gentilello et al., 1999; Monti et al., 1999; Longabaugh et al., 2001). Alcohol-dependence treatment has also been shown to be effective for reducing drink-driving offences (Dinh-Zarr et al., 1999).

However, the main evidence comes from the meta-analysis carried out by Wells-Parker et al. (1995) 10 years ago. The study was based on 215 studies carried out on convicted drink-driving offenders, and revealed that treatment (alcohol abuse treatment and rehabilitation interventions) reduces reoffending and alcohol-related collisions to a greater extent than conventional criminal justice measures (fines, licence suspensions, etc.).

Alcohol-dependent patients are not considered fit to drive. Current EU legislation (please visit the Driving Licence website, http://www.europa.eu.int/comm/transport/index_en.htlm) does not permit the issuing or renewal of driving licences to those who do not possess adequate driving ability. Annex III of Council Directive 91/439/CEE on driving licences establishes the minimum standards of physical and mental fitness for driving a power-driven vehicle. Under the heading referring to alcohol, it establishes that "driving licences shall not be issued to, or renewed for, applicants or drivers who are dependent on alcohol or unable to refrain from drinking and driving. After a proven period of abstinence and subject to authorized medical opinion and regular medical check-ups, driving licences may be issued to, or renewed for, applicants or drivers who have in the past been dependent on alcohol" (Del Río et al., 2001; Alvarez et al., 2005).

In the European Union subjects are allowed to drive again after successful treatment. However, it is not known whether this decision is a good one or not. The aim of this study, then, is to examine whether the high risk of alcohol-related problems in traffic is modified by treatment for alcohol-dependent drivers.

\section{Objectives}

The aim of the study is to analyse the effect on traffic accidents of treatment of patients with alcohol-related problems. To do so, the prevalence of traffic problems in a sample of patients with a diagnosed dependence on alcohol was assessed for three periods: during their lifetime, in the year preceding the start of treatment and over the year of treatment.

\section{Methods}

The criteria for inclusion in the study are as follows: Firstly, patients attending participating centres for the first time to treat their dependence on alcohol (Gómez-Talegón and Álvarez, 2005). Secondly, that such patients have a valid driving licence. Thirdly, that they regularly drive at the present time (at least $2000 \mathrm{~km}$ a year). All the patients were adequately informed of the nature of the study and participated voluntarily, giving their consent in writing.

As pointed out previously, EU legislation and Spanish legislation established that driving licences shall not be issued to, or renewed for applicants or drivers who are dependent on alcohol (Del Río et al., 2001). Spanish legislation establishes that to obtain a driving licence, or to renew it (every ten years up to 45 , every 5 years between 46 and 70 and every 2 years from 70 onwards), a medical-psychological examination, carried out in specific 'Medical Driving Test Centres', is obligatory. In these Medical Driving Test Centres, medical, eyesight and psychological tests are carried out with a view to assessing fitness to drive in accordance with Spanish legislation (Royal Decree 772/1997). After the medical-psychological evaluation drivers could be rated as fit to drive, fit to drive with restrictions (the driver is allowed to drive but under certain conditions, as for example a shortening of the validity of the driving licence or a speed limitation), and unfit (not allowed to drive). All the patients included in the study were evaluated by the Medical Driving Test Centres as fit or fit to drive with restrictions.

All the patients were diagnosed as alcohol dependent according to the DSM-IV criteria (APA, 1994). The diagnosis in each centre was carried out by the physician. During evaluation, at least CAGE (Ewing, 1984), AUDIT (Saunders et al., 1993) and MALT (Feuerlein et al., 1977) tests were carried out for all patients in their validated Spanish versions (Rodriguez-Martos et al., 1986; Rubio et al., 1998; Rodriguez-Martos and Súarez, 1984, respectively).

The information collected includes: (i) socio-demographic data (sex, age), (ii) patterns of alcohol consumption (frequency, type of beverage and quantity of alcohol consumed), (iii) information concerning whether the patients had had traffic problems related to their alcohol consumption and what the problems were. When possible, this information was verified with the relatives who accompanied patients to the Test Centre. Information was collected on the following traffic problems.

\subsection{Positive breath tests, that is, when the patient reported undergoing a breath alcohol test at the request of the police and which gave a positive result}

In accordance with Spanish legislation, motor vehicle users are not allowed to drive if their blood alcohol concentration is greater than $0.5 \mathrm{~g} / \mathrm{l}$ (or $0.25 \mathrm{mg} / \mathrm{l}$ in exhaled air). These limits are $0.3 \mathrm{~g} / \mathrm{l}(0.15 \mathrm{mg} / \mathrm{l}$ in exhaled air $)$ for users of vehicles intended 
for transporting goods, passengers/school children, hazardous goods, special transportation, etc. as well as for any operator in the first 2 years after obtaining a driving licence or permit (Del Río et al., 2001).

Police officers responsible for traffic can ask anyone to undergo such a test (a breath alcohol test) when (i) involved in an accident; (ii) the driver has committed a traffic violation; (iii) at any preventive alcohol control; (iv) whenever the officers observe behaviour on the part of drivers that reasonably leads to the assumption that they are driving under the influence of alcohol (Del Río et al., 2001).

\subsection{Traffic accidents where the patient is a pedestrian}

\subsubsection{Traffic accidents where the patient is the driver,} specifying whether the accident caused: (i) injuries, (ii) deaths, (iii) damage to the vehicle only

Traffic problems have been evaluated for three different periods: (i) during the patient's lifetime, (ii) in the year prior to the start of treatment and (iii) during the year of treatment.

The treatment centres participating in the study are specific day centres for treating alcoholism in which programmes are applied with the aim of achieving abstinence from the consumption of alcohol and programmes to reduce the effect on persons who cannot maintain an absolute abstinence from alcohol. The participants in this study were all included in programmes of treatment whose aim was to achieve abstinence from the consumption of alcohol. The duration of the treatment is individualised for each patient, depending on their characteristics and the evolution of their dependence.

A prospective study has been designed. The patients participating in the study were those attending three alcoholism treatment centres of Castilla y León (Spain) for treatment of their alcohol-dependence problem between June 2002 and 2003. Even though the treatment was over a year in duration, the information collected concerning the traffic problems of the patients refers to the 12 months of treatment, information being collected at monthly intervals.

In one of the participating centres, the treatment has an eminently psychosocial basis, with medical treatment for the health problems produced by the excessive consumption of alcohol, and also self-help therapies (twice a week), led by psychologists or ex-alcoholic monitors with special training. The aim of this treatment is to achieve and maintain abstinence. Its duration is not totally defined as this depends on the evolution and development of the patient. It can vary between 2 and 4 years. Interested patients can remain in the centre as long as they like, as ex-alcoholics, helping other patients in their rehabilitation. The other two participating centres offer an eminently medical programme of treatment with monthly visits to the doctor or psychologist. The aim is abstinence from the consumption of alcohol and the duration of the treatment varies between 2 and 3 years.

The study includes 176 patients, $83.5 \%(n=147)$ male and $16.5 \%(n=29)$ female. The average age was $42.93 \pm 9.89$ years (mean \pm S.D.), $43.11 \pm 10.23$ in males and $42.03 \pm 8.04$ in females $(F=0.28, p>0.05) .52 .8 \%$ were married, $24.5 \%$ sin- gle, $21.6 \%$ were divorced, and $1.1 \%$ were widowed. $53.4 \%$ had primary studies, $31.8 \%$ intermediate studies, $9.7 \%$ university degrees, and $5.1 \%$ no schooling. $64.2 \%$ lived in urban areas, $11.4 \%$ in towns with between 5000 and 50,000 inhabitants, and $24.2 \%$ in rural areas (less than 5000 inhabitants).

Before the start of treatment the majority were daily consumers of alcohol, with an average of $139.65 \mathrm{~g}$ of absolute alcohol/day (S.D. \pm 254.27$)$, males $145.43 \pm 275.48$ and females $110.34 \pm 85.46 \quad(F=0.460, p>0.05)$. Mean \pm S.D. scores were $2.97 \pm 0.62$ for CAGE, 20.34 \pm 3.28 for AUDIT and $31.24 \pm 8.66$ for MALT (total scores, objective and subjective scales). The majority of patients seek treatment because of family concern and self-concern. No-one was seeking treatment due to a court order because of a drink-driving collision or arrest.

The statistical package SPSS, version 11.5 was used. Values of $p \leq 0.05$ were considered statistically significant.

\section{Results}

\subsection{Traffic problems during their lifetime}

$36.9 \%$ of participants reported traffic problems during their lifetime (Table 1). No significant differences were observed with respect to age $\left(\chi_{3}^{2}=2.789, p>0.05\right)$. The mean $( \pm$ S.D. $)$ number of traffic problems among those reporting them was $1.35 \pm 0.48$. Positive alcohol breath tests (resulting in a fine and withdrawal of the licence to drive), were admitted to by $26.7 \% .22 .1 \%$ admitted to accidents as drivers, mainly with damage to the vehicle alone $(14.2 \%)$, and less frequently with injuries $(7.4 \%)$ or deaths $(0.6 \%)$. Accidents as pedestrians were admitted to by $1.1 \%$.

\subsection{Traffic problems in the year prior to starting treatment}

$8.5 \%$ of patients, all male $(10.2 \%)$, reported traffic problems in the year prior to starting treatment (Table 1), no difference was observed with respect to age $\left(\chi_{3}^{2}=1.877, p>0.05\right)$, although traffic problems in the year prior to treatment are more frequently reported by the youngest, decreasing as the age range increases. The mean $( \pm$ S.D.) number of traffic problems in the previous year among those who admitted to them was $1.06 \pm 0.25$. Positive alcohol breath tests were reported by $7.4 \%$ (Table 1), accidents as drivers by $1.7 \%$, of which $0.6 \%$ involved injuries and $1.1 \%$ damage to vehicles. No accidents as pedestrians were reported.

\subsection{Traffic problems over the 12 months of treatment for alcohol dependence}

Throughout the treatment and monthly checks on the patients there was a progressive rate of drop-out from the programme from the 1 st to the 12 th month, with $39.2 \%(n=69)$ of patients remaining at the end of the year, $38.1 \%(n=56)$ male and $44.8 \%$ $(n=13)$ female $\left(\chi^{2}=0.461, p>0.05\right)$.

In this period, three separate individual problems were reported. Each problem was reported by a different patient. The first was reported in the fourth month of treatment, when $56.25 \%(n=99)$ of the patients in the study remained. The sec- 


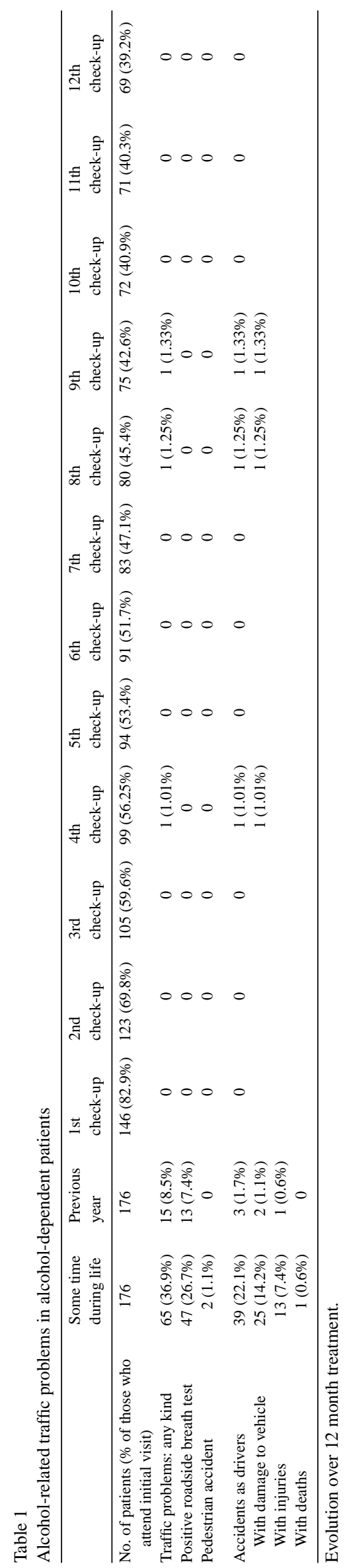

ond was reported in the eighth month with $45.4 \%(n=80)$ of the patients remaining and the third was reported in the ninth month with $42.6 \%(n=75)$ of patients remaining. The type of accident reported was damage to the vehicle in all three cases. No further problems were reported over the 12 months covering the treatment.

\subsection{Traffic problems when only considering those patients who complete the treatment}

Given that only about a third ( 69 of 176 ; males $n=56,81.2 \%$; females $n=13,18.8 \%$ ) of the alcohol-dependent patients completed the 12 months of treatment, Table 2 shows the traffic problems reported by these 69 patients throughout their lives (29\%), in the year prior to starting treatment (15.9\%) and during the year of treatment $(4.3 \%)$.

The prevalence of traffic problems among these patients during treatment $(4.3 \%)$ was noticeably lower $(p<0.05$ in the $\mathrm{McNemar}$ test) than in the year before treatment (15.9\%). That is, there was a decrease of $11.6 \%$.

While, in the year before treatment, 10 out of 11 patients (Table 2) with traffic problems reported positive breath tests, during the 12 months of treatment for their dependency there were no such cases reported. However, the prevalence of accidents with damage to the vehicle was $1.4 \%$ in the year prior to treatment and $4.3 \%$ during treatment ( $p>0.05$ in the McNemar test).

Those that completed 12 months of treatment (69) and those that left treatment at some stage (107) did not differ $(p>0.05)$ with regard to sex, age, the centre of treatment, mean daily alcohol intake prior to the start of treatment, or CAGE, AUDIT and MALT mean scores. There are no differences in the prevalence of traffic problems during their lifetime $(p>0.05)$ as well as in the average number of problems referred to $(p>0.05)$. However, the prevalence of traffic problems in the year prior to the start of treatment was higher in those that remained in treatment (15.9\%) than in those who dropped out $(3.7 \%, p<0.005)$, while the average number of problems referred to does not differ $(p>0.05)$.

\section{Discussion}

In our study over a third of patients (36.9\%) had had alcoholrelated traffic problems throughout their lives. The most frequent problem was a positive breath test $(26.7 \%)$, while nearly one out of four patients $(22.1 \%)$ had been involved in a traffic accident, mostly with only damage to the vehicles and less frequently with injuries or deaths. An appreciable percentage of alcohol-dependent patients reported traffic problems $(8.5 \%)$ in the year prior to starting treatment, especially positive breath tests. Patients who follow the treatment for their dependence on alcohol show a decrease in the number of problems. However, this is true only for those who remained in treatment for at least 1 year (39.2\% of the overall sample).

In our study, alcohol-dependent patients showed a high frequency of traffic problems. Other authors have already pointed out that patients with alcohol abuse or dependence have more traffic problems than occasional drinkers or tea-totallers (Kennedy et al., 1996; Snow and Wells-Parker, 2001; Baker et 
Table 2

Traffic problems in patients who completed the one year treatment $(n=69)$

\begin{tabular}{|c|c|c|c|c|c|c|}
\hline & \multicolumn{2}{|c|}{ Some time in their life } & \multicolumn{2}{|c|}{ In the year prior to starting treatment } & \multicolumn{2}{|c|}{ During the 12 month treatment } \\
\hline & $n$ & $\%$ & $n$ & $\%$ & $n$ & $\%$ \\
\hline Traffic problem: any kind & 20 & 29.0 & 11 & 15.9 & 3 & 4.3 \\
\hline Positive roadside breath test & 15 & 21.7 & 10 & 14.5 & 0 & \\
\hline Accidents as pedestrian & 1 & 1.4 & 0 & & 0 & \\
\hline Accidents as drivers & 13 & 18.8 & 1 & 1.4 & 3 & 4.3 \\
\hline With damage to vehicle & 7 & 10.1 & 1 & 1.4 & 3 & 4.3 \\
\hline With injuries & 6 & 8.7 & 0 & & & \\
\hline With deaths & 0 & & 0 & & & \\
\hline Mean of traffic problems & 1.45, S.D. $=0.51$ & & 1, S.D. $=0$ & & 1, S.D. $=0$ & \\
\hline
\end{tabular}

al., 2002; Hingson et al., 2002). The fact that males are seen to have traffic problems more frequently that women has also been referred to (Hingson and Winter, 2003; Kennedy et al., 1996). Alcoholism is the most common chronic disease among trauma patients: it is estimated that from $25 \%$ to $40 \%$ of patients treated in major trauma centres are alcoholics. Thus, screening for alcohol-related problems among trauma patients, as well as intervention (from brief counselling to referral for alcoholdependence treatment) is of relevance, although in practice this is poorly enforced (NHTSA, 2000; Runge, 2000).

It is well known that there is a marked drop-out rate among alcohol-dependent patients during treatment (Noone and Watt, 2000; Chick et al., 2000). This is reflected in our study, the initial number of patients included was 176 and after the 12 months of treatment, more than half (107) had dropped out, with only 69 patients remaining in the study.

No positive breath tests were found in any of the patients who completed the 12 months of treatment. It should be taken into account that the aim of the programmes is to achieve total abstinence from alcohol. As already pointed out, if patients undergoing treatment for alcohol dependence do not drink, then it is highly improbable that they will have positive breath tests (Chipman et al., 2003).

Our study shows a decrease in traffic problems among alcohol-dependent patients who complete one year's treatment, the percentage passing from $15.9 \%$ to $4.3 \%$, which agrees with existing scientific evidence (Wells-Parker et al., 1995; Macdonald et al., 2004). In this sense, a recent report carried out on alcohol-related problems for patients in treatment $(n=117)$ shows that these patients have a higher traffic violation and collision rate than matched controls. This study also assessed whether or not a reduction in traffic events and collisions after treatment had occurred in relation to pre-treatment and in comparison with a matched control group. The average number of collisions for the alcohol group decreased after treatment, whereas the control group remained stable (Macdonald et al., 2004). On the other hand, those with alcohol-related problems who had been involved in traffic accidents, do not change their drinking habits if they do not follow a course of treatment (Mayou and Bryant, 1995).

Our study has a series of limitations. Firstly, the data concerning accidents are reported by patients themselves in personal interviews, which can lead to minimisation of data due to underreporting or non-reporting of possible problems so as not to endanger their therapy; unlike other works in which the data concerning traffic problems was obtained from databases belonging to the police and traffic authorities (Macdonald et al., 2004). In order to avoid or minimise this, the information reported by patients was confirmed by reports from relatives, although confirmation was not possible in all cases. Furthermore, for legal reasons, we were not allowed access to police databases on sanctions and road traffic accidents.

Secondly, there is a limitation with respect to the evaluation of the traffic problems, as only positive breath tests are considered traffic violations and not other violations, while, for collisions, all the possibilities have been considered (with injuries, deaths and damage to vehicles).

However, this study presents the advantage that all these traffic violations and collisions have been reported by the patient as due to the influence of alcohol, while, in studies where data on accidents are obtained from databases belonging to the police or traffic authorities, it is not always possible to say whether alcohol was the cause or not.

Thirdly, this is a prospective study and, as expected, there has been a considerable drop-out rate. In this sense, information concerning patients who have dropped out is not known. Patients that remained in treatment and those that dropped out do not differ in socio-demografic aspects, in previous alcohol intake prior to the start of treatment, or in the screening test used (CAGE, AUDIT, MALT). Lifetime prevalence of traffic problems did not differ, while those that remained in treatment referred to a higher prevalence of past year traffic problems than those that did not complete the treatment. When evaluating the possible reduction in the occurrence of traffic accidents with treatment, it would seem to be more coherent to compare data of patients who complete 12 months of the treatment.

Unlike other studies, the present prospective study was designed without a control group not undergoing treatment for matching with the patients (Macdonald et al., 2004). This lack does not allow us to establish whether or not such a reduction in traffic problems would take place in the control group and nor does it allow us to compare both groups.

Exposure is a key element for establishing the effect of the alcohol-dependence treatment on traffic problems. Controlling 
for exposure is not easy. In the present study one requeriment was actual driving, and a minumum of at least $2000 \mathrm{~km}$ a year.

Linked to this matter of exposure is whether or not alcoholdependent patients have a valid driving licence or not. All participating patients were checked by the Medical Driver Test centres and found fit to drive or fit to drive with some restrictions. No patient unfit to drive was included in the study.

These two aspects allow us to consider that the reduction in traffic problems among alcohol-dependent patients who have treatment for 12 months is due to the treatment and not to a change in exposure (driving less frequently, etc.).

This study shows that an important percentage of alcoholdependent patients have alcohol-related traffic problems, and that these problems decrease considerably if they follow a medical-psychosocial treatment for their dependency. A large percentage of patients had positive breath tests. In this sense, it is well known that drivers sanctioned for driving under the effects of alcohol (high blood alcohol level) have a high probability of having alcohol-related problems and that they should undergo a screening for alcohol abuse or dependence (Baker et al., 2002; Donovan et al., 2004; Gentilello et al., 1999). On the other hand, injuries due to traffic collisions are frequent among alcohol-dependent patients and they are frequently admitted to hospital or have recourse to the use of emergency services. It would seem necessary to carry out a brief motivational intervention in such services to reduce the consumption of alcohol (Monti et al., 1999; Longabaugh et al., 2001). The importance of addressing trauma history in the treatment of patients with substance abuse disorders has been pointed out (Farley et al., 2004).

The present study has a clear relevance for driver licensing and regranting driving licences. One of the main results of the study is that alcohol-dependent patients undergoing treatment showed a reduction in traffic problems, even in treatment programmes that are not specifically aimed at reducing or avoiding driving problems but to treat the alcohol depencency. Secondly, current EU legislation on driving licences is quite ambiguous on that matter and there are marked differences between member states in how it is implemented (Alvarez et al., 2005). Furthermore, the regranting of driving licences in cases of alcohol dependence is a matter of discussion and no clear consensus has been reached. The same has been proposed, however, for those driving while impaired by alcohol (Nickel, 1996).

The study has shown that at least for those alcohol-dependent patients who remain in treatment for at least 1 year, the treatment is also effective in reducing the number of alcohol-related problems. Thus, from these results it makes sense to allow alcohol-dependent drivers to drive again if they have successfully completed a course of treatment. Further studies are needed to establish the length of treatment before drivers are once more allowed to drive.

\section{Acknowledgements}

This study has been supported by a grant from the 'Delegación del Gobierno para el Plan Nacional sobre Drogas and the Consejería de Familia e Igualdad de Oportunidades', as well as by a grant for the development of 'Redes Temáticas de Investigación Cooperativa', 'Red de Trastornos Adictivos G03/005'. We also wish to express our gratitude to the professionals who work in the Alcoholism Treatment Centres that participated in the study (A.R-VA, Alcohólicos Rehabilitados de Valladolid) and to Sanchez F. and Marcos A. (Red Cross, Valladolid and Soria).

\section{References}

Alvarez, F.J., Gómez, M.T., Fierro, I., 2005. The use and usability of CD 91/439 on driving licences. Deliverable D-P4.3 of EU project IMMORTAL. University of Valladolid, Valladolid. http://www.immortal.or.at.

American Psychiatric Association (APA), 1994. Diagnostic and Statistical Manual of Mental Disorders, 4th ed. APA, Washington, DC.

Baker, S.P., Braver, E.R., Chen, L.H., Li, G., Williams, A.F., 2002. Drinking histories of fatally injured drivers. Inject. Prev. 8 (3), 221-226.

Chick, J., Howlett, H., Morgan, M.Y., Ritson, B., 2000. United Kingdom Multicentre Acamprosate Study (UKMAS): a 6-month prospective study of acamprosate versus placebo in preventing relapse after withdrawal from alcohol. Alcohol. Alcohol 35 (2), 176-187.

Chipman, M.L., Macdonald, S., Mann, R.E., 2003. Being "at fault" in traffic crashes: does alcohol, cannabis, cocaine, or polydrug abuse make a difference? Inject. Prev. 9 (4), 343-348.

Chipman, M.L., 1995. Risk factors for injury: similarities and differences for traffic crashes and other causes. Accid. Anal. Prev. 27 (5), 699-706.

Del Río, M.C., González-Luque, J.C., Alvarez, F.J., 2001. Alcohol-related problems and fitness to drive. Alcohol. Alcohol 36 (3), 256-261.

Dinh-Zarr, T., Diguiseppi, C., Heitman, E., Roberts, I., 1999. Preventing injuries through interventions for problem drinking: a systematic review of randomized controlled trials. Alcohol. Alcohol 34 (4), 609-621.

Donovan, D.M., Dunn, C.W., Rivara, F.P., Jurkovich, G.J., Ries, R.R., Gentilello, L.M., 2004. Comparison of trauma center patient self-reports and proxy reports on the Alcohol Use Identification Test (AUDIT). J. Trauma 56 (4), 873-882.

Ewing, J.A., 1984. Detecting alcoholism: the CAGE questionnaire. JAMA 252 (14), 1905-1907.

Farley, M., Golding, J.M., Young, G., Mulligan, M., Minkoff, J.R., 2004. Trauma history and relapse probability among patients seeking substance abuse treatment. J. Subst. Abuse Treat. 27 (2), 161-167.

Feuerlein, W., Ringer, C., Küfner, K.A., 1977. Diagnose des alkoholismus: Der Müncher Alkolismustes (MALT). Münch. Med. Wochf. 119 (40), 1275-1282.

Gentilello, L.M., Rivara, F.P., Donovan, D.M., Jurkovich, G.J., Daranciang, E., Dunn, C.W., Villaveces, A., Copass, M., Ries, R.R., 1999. Alcohol interventions in a trauma center as a means of reducing the risk of injury recurrence. Ann. Surg. 230 (4), 473-483.

Gómez-Talegón, M.T., Álvarez, F.J., 2005. Demand for Prior Treatment in Alcoholic Patients. Subst Use Misuse 40, in press.

Haberman, P.W., 1987. Alcohol and alcoholism in traffic and other accidental deaths. Am. J. Drug Alcohol Abuse 13 (4), 475-484.

Hingson, R., Winter, M., 2003. Epidemiology and consequences of drinking and driving. Alcohol Res. Health 27 (1), 63-78.

Hingson, R., Heeren, T., Levenson, S., Jamanka, A., Voas, R., 2002. Age of drinking onset, driving after drinking, and involvement in alcohol related motor-vehicle crashes. Accid. Anal. Prev. 34 (1), 85-92.

Kennedy, B.P., Isaac, N.E., Graham, J.D., 1996. The role of heavy drinking in the risk of traffic fatalities. Risk Anal. 16 (4), 565-569.

Longabaugh, R., Woolard, R.E., Nirenberg, T.D., Minugh, A.P., Becker, B., Clifford, P.R., Carty, K., Licsw, Sparadeo, F., Gogineni, A., 2001. Evaluating the effects of a brief motivational intervention for injured drinkers in the emergency department. J. Stud. Alcohol 62 (6), 806816.

Macdonald, S., Mann, R.E., Chipman, M., Anglin-Bodrug, K., 2004. Collision and traffic violations of alcohol, cannabis and cocaine abuse clients before and after treatment. Accid. Anal. Prev. 36 (5), 795-800. 
Maycock, G., 1997. Drinking and driving in Great Britain—a review. TRL Report 232. TRL, Crowthorn.

Mayou, R., Bryant, B., 1995. Alcohol and road traffic accidents. Alcohol. Alcohol 30 (6), 709-711.

Monti, P.M., Colby, S.M., Barnett, N.P., Spirito, A., Rohsenow, D.J., Myers, M., Woolard, R., Lewander, W., 1999. Brief intervention for harm reduction with alcohol-positive older adolescents in a hospital emergency department. J. Consult. Clin. Psychol. 67 (6), 989-994.

National Highway Traffic Safety Administration (NHTSA), 2000. Training physicians about impaired drivers. Ann. Emerg. Med. 36 (6), 628629.

Nickel, W.R., 1996. Medical screening and medical-psychological assessment as prerequisites for regranting licences: summary of recommendations. Alcohol. Alcohol 31 (6), 605-607.

Noone, P., Watt, D., 2000. An audit of NHS Trust alcohol policy referrals to an occupational health service. Health Bull. (Edinb.) 58 (2), 133136.

Rodriguez-Martos, A., Navarro, R.M., Vecino, C., Pérez, R., 1986. Validación de los cuestionarios KFA (CBA) y CAGE para el diagnostico del alcoholismo. Drogaslcohol 11 (4), 132-139.

Rodriguez-Martos, A., Súarez, R., 1984. MALT (Muncher Alkolismus Test), Validación de la version española de este test para el diagnostico del alcoholismo. Rev. Psiquiatr. Psicol. Med. 16 (6), 421-432.
Rubio, G., Bermejo, J., Caballero, M.C., Santo-Domingo, J., 1998. Validación de la prueba para la identificación de trastornos por uso de alcohol (AUDIT) en atención primaria. Rev. Clin. Esp. 198 (1), 11-14.

Runge, J.W., NHTSA Notes Commentary, 2000. Screening for alcohol use disorders-barriers and excuses. Ann. Emerg. Med. 36 (6), 629-630.

Saunders, J.B., Aasland, O.G., Babor, T.F., De la Fuente, J.R., Grant, M., 1993. Development of the Alcohol Use Disorders Identification Test (AUDIT): WHO collaborative project on early detection of persons with harmful alcohol consumption-II. Addiction 88 (6), 791-804.

Schmidt, W., Smart, R.G., Popham, R.E., 1962. The role of alcoholism in motor vehicle traffics accidents. Traffic Saf. Res. Rev. 6 (4), 1-25.

Snow, R.W., Wells-Parker, E., 2001. Relationships between drinking problems and drinking locations among convicted drinking drivers. Am. J. Drug Alcohol Abuse 27 (3), 531-542.

Waller, J.A., Turkel, H.W., 1966. Alcoholism and traffic deaths. N. Engl. J. Med. 275 (10), 532-536.

Wells-Parker, E., Bangert-Drowns, R., McMillen, R., Williams, M., 1995. Final results from a meta-analysis of remedial interventions with drink/drive offenders. Addiction 90 (7), 907-926.

WHO, 2004. World Report on Road Traffic Injury Prevention. World Health Organization, Geneva.

Zador, P.L., 1991. Alcohol-related relative risk of fatal driver injuries in relation to driver age and sex. J. Stud. Alcohol 52 (4), 302-310. 